\title{
Mechanical and Microstructural Characterization of Alkali-Activated Materials Based on Fly Ash and Slag
}

\author{
Maochieh Chi, Yenchun Liu, and Ran Huang
}

\begin{abstract}
This study investigates the mechanical and microstructural characterization of alkali-activated fly ash/slag (AAFS) mortars with various ratios of fly ash to slag. The liquid/binder ratios of $0.35,0.5$ and 0.65 are considered for the AAFS mortars. $4 \%$ Sodium oxide $\left(\mathrm{Na}_{2} \mathrm{O}\right)$ concentration of cementitious material weight in mixture and liquid sodium silicate with modulus ratio (mass ratio of $\mathrm{SiO}_{2}$ to $\mathrm{Na}_{2} \mathrm{O}$ ) of 1 were used as alkaline activators to alkali-activate various fly ash/slag ratios. Compressive strength test, water absorption test, drying shrinkage test, scanning electron microscopy (SEM) and $\mathrm{X}$-ray diffraction (XRD) analysis were conducted. Test results reveal that both fly ash/slag ratio and the liquid/binder ratio are two significant factors influencing the mechanical and microstructural characterization of AAFS mortars. The hydration products of AAFS mortars are mainly amorphous alkaline aluminosilicate and low-crystalline calcium silicate hydrate gel.
\end{abstract}

Index Terms_Alkali-activated fly ash/slag, liquid/binder ratio, scanning electron microscopy (SEM), X-ray diffraction (XRD).

\section{INTRODUCTION}

In recent years, different kinds of alkali-activated cementitious materials have been developed because of their high strength and durability and low environmental impact [1]. Alkali-activated cementitious materials are made by mixing industrial aluminosilicate waste materials such as fly ash (FA) [2] or ground granulated blast furnace slag (GGBFS) [3]with an alkaline activating solution [4]. FA and GGBFS are are two types of solid waste materials with some similarities [5]. Both are calcium aluminosilicate glasses but their reaction products are quite different. The major binding phase in alkali-activated GGBFS [6] is calcium silicate hydrate (C-S-H) [7] while alkali-activated class F fly ash is the amorphous hydrated alkali-aluminosilicate [8]. These two types of cements have been investigated to substitute for binder to compose cementless mortar or concrete because of their special characteristics and the typical representation of alkali-activated cements [9].

Alkali-activated slag cements have excellent mechanical strength [10]. Higher compressive strength and flexural

Manuscript received January 6, 2014; revised April 20, 2014.

Maochieh Chi is with the Department of Fire Science, WuFeng University, Chiayi County, 621 Taiwan (e-mail: jackchi@wfu.edu.tw).

Yenchun Liu is with the Graduate School of Opto-Mechatronics and Materials, WuFeng University, Chiayi County, 621 Taiwan (e-mail: blliu@wfu.edu.tw).

Ran Huang is with the Department of Harbour and River Engineering, National Taiwan Ocean University, Keelung, 200 Taiwan (e-mail: ranhuang@mail.ntou.edu.tw). strength have been obtained in alkali-activated GGBFS mortars or concretes than comparable OPC mortars or concretes [11]. However, its drying shrinkage of alkali-activated slag concrete is higher than that of OPC concrete [12]. In contrast, fly ash based alkali-activated mortars or concretes usually exhibit a slower setting and strength development [13]. The key factors influencing their potential reactivity are the reactive silica content, the vitreous phase content and the particle size distribution [2]. Palomo et al. [14] reported that temperature, curing time of specimens and solution/fly ash ratio have a significant influence on the mechanical strength of the alkali-activated fly ash pastes. Xie and $\mathrm{Xi}$ [15] investigated the hardening mechanisms of an alkaline-activated class F fly ash and concluded that the strength of the paste increased with the decrease of the modulus of water-glass from 1.64 to 1.0. Puertas et al. [16] studied the strength behavior and hydration products of fly ash/slag pastes activated with $\mathrm{NaOH}$ and found that the compressive strength of the specimen with $50 \%$ fly ash $/ 50 \%$ slag activated with $10 \mathrm{M} \mathrm{NaOH}$ solution and cured at the temperature of $25^{\circ} \mathrm{C}$ was more that $50 \mathrm{MPa}$ at the age of 28 days. The fly ash/slag ratio is the most relevant factor on the strength development [9]. Zhao et al. [17] studied the strength of alkali-activated $20 \%$ fly ash $/ 80 \%$ slag blended cement and found that the compressive strength of the cement mortar is up to $49 \mathrm{MPa}$ and flexural strength $8.4 \mathrm{MPa}$ at the age of 28 days. Shi and Day [18] concluded that the addition of a small amount of hydrated lime significantly increased the early-age strength of fly ash/slag mixtures activated by $\mathrm{HaOH}$ and sodium silicate.

Most previous studies deal only with alkali-activated slag or fly ash, as for the combined use of both, relatively little information is reported [1]. How to merge the two kinds of materials into one to complement each other in performance is an important issue and needs further research. This study aims at investigating the mix-design and properties of alkali-activated fly ash/slag (AAFS) mortars. Three liquid/binder ratios of $0.35,0.5$ and 0.65 were chosen to produce the OPC mortars and AAFS mortars with fly ash/slag ratios of $100 / 0,50 / 50$, and $0 / 100$. Sodium oxide $\left(\mathrm{Na}_{2} \mathrm{O}\right)$ concentrations of $4 \%$ of cementitious materials weight and liquid sodium silicate with modulus ratio (mass ratio of $\mathrm{SiO}_{2}$ to $\mathrm{Na}_{2} \mathrm{O}$ ) of 1 were used as alkaline activators to activate various fly ash/slag ratios. Compressive strength test, water absorption test, drying shrinkage test, scanning electron microscopy (SEM) and X-ray diffraction analysis of AASF mortars were performed. Furthermore, their performance was discussed and compared with reference mortars produced using OPC. 


\section{EXPERIMENTAL PROGRAM}

\section{A. Materials}

TABLE I: CHEMICAL COMPOSITIONS OF OPC, FFA AND GGBFS

\begin{tabular}{|l|c|c|c|}
\hline Chemical compositions (\%) & OPC & FFA & GGBFS \\
\hline Calcium oxide, $\mathrm{CaO}$ & 63.56 & 2.82 & 40.67 \\
\hline Silicon dioxide, $\mathrm{SiO} 2$ & 21.04 & 56.48 & 34.58 \\
\hline Aluminum oxide, $\mathrm{A} 12 \mathrm{O} 3$ & 5.46 & 20.34 & 13.69 \\
\hline Ferric oxide, Fe2O3 & 2.98 & 6.61 & 0.44 \\
\hline Sulfur trioxide, $\mathrm{SO} 3$ & 2.01 & 0.25 & 0.56 \\
\hline Sodium oxide, Na2O & 0.32 & 0.33 & 0.15 \\
\hline Potassium oxide, K2O & 0.70 & 0.8 & 0.32 \\
\hline Magnesium oxide, MgO & 2.52 & 0.93 & 7.05 \\
\hline Loss on ignition, L.O.I. & 1.38 & 2.76 & 1.13 \\
\hline Others & 0.03 & 8.68 & 1.41 \\
\hline
\end{tabular}

The samples were prepared using Ordinary Portland cement (OPC) type I, Class F Fly ash (FFA) and Ground granulated blast furnace slag (GGBFS) as raw materials. FFA was obtained from the Xingda Power Plant, Taiwan. The specific gravity of the FFA was 2.06 and its Blaine specific surface area was about $237 \mathrm{~m}^{2} / \mathrm{kg}$. GGBFS was supplied by $\mathrm{CHC}$ Resources Corporation, Taiwan. The specific gravity of the GGBFS was 2.88 and its Blaine specific surface area was about $435 \mathrm{~m}^{2} / \mathrm{kg}$. OPC with a specific gravity of 3.15 and a
Blaine specific surface area of $364 \mathrm{~m}^{2} / \mathrm{kg}$ was used as reference binder. The chemical composition of OPC, FFA and GGBFS is shown in Table I. River sand was used as a fine aggregate in the manufacture of mortars. The fineness modulus, bulk density and absorption of fine aggregate were $2.54,2540 \mathrm{~kg} / \mathrm{m}^{3}$ and $2 \%$, respectively. Chemical reagent $\mathrm{NaOH}$ pellets with a density of $2130 \mathrm{~kg} / \mathrm{m}^{3}$ and sodium silicate solution $\left(\mathrm{Na}_{2} \mathrm{O} \cdot \gamma \mathrm{SiO}_{2} \cdot \mathrm{nH}_{2} \mathrm{O}\right)$ composed of $29.2 \%$ $\mathrm{SiO}_{2}, 14.8 \% \mathrm{Na}_{2} \mathrm{O}$ and $56.0 \% \mathrm{H}_{2} \mathrm{O}$ by mass were used as activator.

\section{B. Mixes Design and Specimens Preparation}

The proportion design for samples was mainly controlled by adjusting liquid/binder ratios $(0.35,0.5$ and 0.65$)$ and fly ash/slag ratios $(100 / 0,50 / 50$, and 0/100). The sand-binder ratio is fixed at 2.75 . The level of sodium oxide $\left(\mathrm{Na}_{2} \mathrm{O}\right)$ concentrations by $4 \%$ expressed as percentage of cementations materials weight in mixtures and liquid sodium silicate with modulus ratios (mass ratio of $\mathrm{SiO}_{2}$ to $\mathrm{Na}_{2} \mathrm{O}$ ) of 1 was used as alkaline activators to alkali-activate FFA and GGBFS. The mixes design was listed in Table II. The specimens were cast and kept in steel molds for 24 hours, and then they were demoded and moved into a curing room at relative humidity of $80 \% \mathrm{RH}$ and the temperature of $25^{\circ} \mathrm{C}$ until testing. The specimens were tested in triplicate sets until the time of testing.

TABLE II: MIX PROPORTIONS OF OPC AND AAFS MORTARS (KG/M $\left.{ }^{3}\right)$

\begin{tabular}{|c|c|c|c|c|c|c|c|}
\hline Mix* & Water & Cement & FA & GGBFS & $\begin{array}{c}\text { Fine } \\
\text { Agg. }\end{array}$ & $\mathrm{Na}_{2} \mathrm{SiO}_{3}$ & $\mathrm{NaOH}$ \\
\hline LCO & 201 & 574 & - & - & 1581 & - & - \\
\hline LF & 108 & - & 574 & - & 1581 & 78.7 & 14.6 \\
\hline LSF & 108 & - & 287 & 287 & 158 & 78.7 & 14.6 \\
\hline LS & 108 & - & - & 574 & 1581 & 78.7 & 14.6 \\
\hline MCO & 264 & 528 & - & - & 1453 & - & - \\
\hline MF & 178 & - & 528 & - & 1453 & 72.3 & 13.4 \\
\hline MSF & 178 & - & 264 & 264 & 1453 & 72.3 & 13.4 \\
\hline MS & 178 & - & - & 528 & 1453 & 72.3 & 13.4 \\
\hline HCO & 317 & 488 & - & - & 1345 & - & - \\
\hline HF & 241 & - & 488 & - & 1345 & 66.9 & 9.6 \\
\hline HSF & 241 & - & 244 & 244 & 1345 & 66.9 & 9.6 \\
\hline HS & 241 & - & - & 488 & 1345 & 66.9 & 9.6 \\
\hline
\end{tabular}

The liquid/binder ratios of $0.35,0.5$ and 0.65 are with symbols $\mathrm{L}, \mathrm{M}$ and $\mathrm{H}$, respectively.

\section{Methods}

The compressive strength tests of the specimens were conducted according to ASTM C109/C109M-11b [19]. For each mixture, cubic specimens with $50 \times 50 \times 50 \mathrm{~mm}^{3}$ dimensions were prepared and tested to determine the average compressive strength at the ages of 7,14 , and 28 days.

Water absorption was made in accordance with ASTM C642-06 [20]. For the water absorption test, the specimens were first kept in an oven at $105 \pm 5^{\circ} \mathrm{C}$ for $24 \mathrm{~h}$ and weighed $\left(W_{d}\right)$. They were then immersed in water for $24 \mathrm{~h}$ and weighed again $\left(W_{s}\right) . W_{s}$ was taken as the saturated weight. It took up to 24 hours for the specimens. The water absorption $(W A)$ was then calculated by the following formula [21]:

Water Absorption: $W A(\%)=(W s-W d) / W d \times 100 \%$

The drying shrinkage test was done in accordance with
ASTM C596-09 [22]. Prismatic specimens with $285 \times 25 \times 25$ $\mathrm{mm}^{3}$ dimensions were prepared and then demolded in one day. Specimens were placed in the humidity cabinet (relative humidity of $80 \%$ ) at the temperature of $25^{\circ} \mathrm{C}$. After three days, the initial length $(L i)$ of the shrinkage specimens was measured before placing them in the curing room. The length $\left(L_{x}\right)$ of the shrinkage specimens was measured at the age of 7 , 14 , and 28 days, respectively. The length change was then calculated by the following formula:

$$
\text { Length Change : } L C(\%)=(L i-L x) / G \times 100 \%
$$

where $G$ is the nominal effective length.

The specimens with dimensions of $10 \times 10 \times 3 \mathrm{~mm}^{3}$ from $50 \mathrm{~mm}$ cubes at the age of 28 days were prepared. Prior to SEM analyses, representative samples were air-dried first, followed by resin impregnation. The impregnated specimens were ground and softly polished with sand paper down to 
$0.25 \mu \mathrm{m}$. SEM analyses were performed using a HITACHI S-4100 microscope with an energy dispersive Spectroscopy (EDS). Randomly oriented powder specimens (about 1 gram weight) for XRD analysis were prepared by grinding small portions of the dried specimens. XRD graphs were obtained by a Siemens D5000 $X$ diffract meter using CuK $\alpha$ radiation at room temperature. The diffract grams were scanned from $10^{\circ}$ to $80^{\circ}$ in the $2 \theta$ and scanning rate was at $0.05^{\circ}$ intervals. Peak positions were determined by fitting the data with pseudo-voigt profiles using the XFIT program.

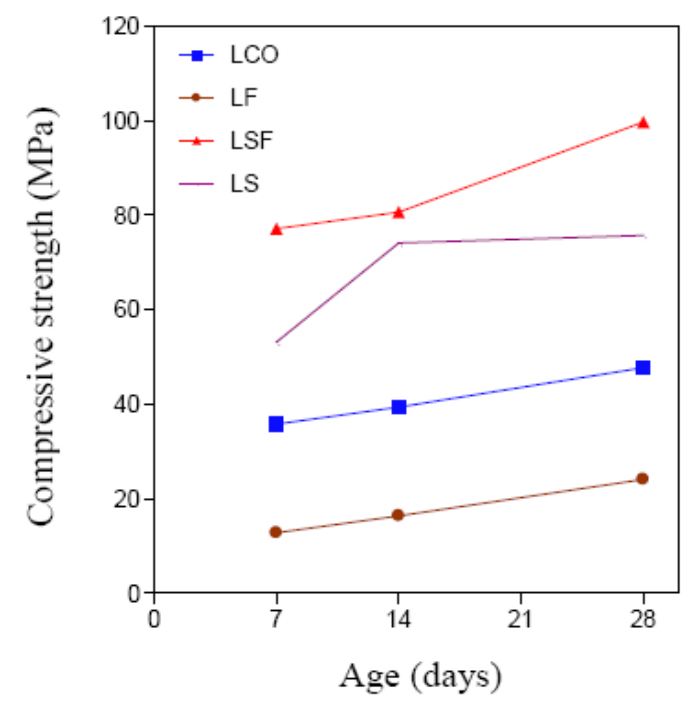

Fig. 1. Compressive strength development of OPC and alkali-activated FFA and/or GGBFS mortars at the liquid/binder ratio of 0.35 .

\section{RESUlTS AND DisCUSSION}

\section{A. Compressive Strength}

The compressive strength development of OPC mortars and AAFS mortars at the ages of 7, 14 and 28 curing days is shown in Fig. 1-Fig. 3. As shown in Fig. 1, AAFS mortar with fly ash/slag ratio of 50/50 (LSF) has the higher compressive strength at all ages than any other three mortars. The compressive strength of LSF is 77,81 and $100 \mathrm{MPa}$ at the ages of 7, 14 and 28 days, respectively. Followed in descending order of the compressive strength are the AAFS mortars with fly ash/slag ratio of 0/100 (LS), OPC mortars (LCO), and AAFS mortars with fly ash/slag ratios of $100 / 0$ (LF). The compressive strength of all mixes increases with an increasing ages. At the ages of 7 and 14 days, the compressive strengths of LS increased sharply. It is because the strength increment with increasing fineness is more pronounced at early ages ( $<14$ days) rather than at later ages [23]. Between 14 and 28 days, the compressive strength gain of LS levels off, whereas LSF continues to gain strength. As shown in Fig. 2, the compressive strength is divided into two groups: more than $50 \mathrm{MPa}$ and lower $50 \mathrm{MPa}$ at all ages. AAFS mortars with fly ash/slag ratios of 50/50 and 0/100 (MSF and MS) belong to the higher compressive strength group and OPC mortar (HCO) and AAFS mortars with fly ash/slag ratios of $100 / 0$ (MF) belong to the lower compressive strength group. At the ages of 7 and 14 days, the compressive strengths of MSF and MS are almost very similar, which is $64 \mathrm{MPa}$ in MSF and $63 \mathrm{MPa}$ in MS at the ages of 14 days, respectively. However, between 14 and 28 days, the compressive strength gain of MS levels off, whereas MSF continues to gain strength, which is $88 \mathrm{MPa}$ in MSF and $64 \mathrm{MPa}$ in MS at the ages of 28 days, respectively. As shown in Fig. 3, it is interesting to noted that the higher compressive strength has been obtained in AAFS mortar with fly ash/slag ratio of $0 / 100$ (HS) at all ages than any other three mortars, followed by AAFS mortars with fly ash/slag ratios of 50/50 (HSF), OPC mortars (HCO), and AAFS mortars with fly ash/slag ratios of 100/0 (HF). The higher the fineness the higher the compressive strength within an extended range of fineness when keeping liquid/binder ratios the same without taking workability into account and the optimum range of fineness $4000-5500 \mathrm{~cm}^{2} / \mathrm{g}$ for basic slags [23]. In this study, the Blaine specific surface area of GGBFS was about $435 \mathrm{~m}^{2} / \mathrm{kg}$, which is higher than those of OPC and FFA. Between 7 and 28 days, the slope of the strength-growth curves for HS and HSF is almost identical to HCO.

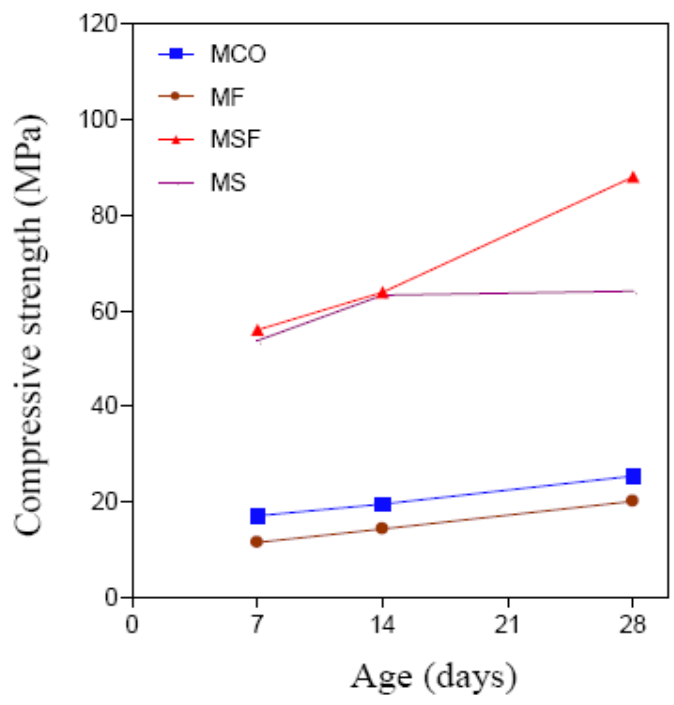

Fig. 2. Compressive strength development of OPC and alkali-activated FFA and/or GGBFS mortars at the liquid/binder ratio of 0.5 .

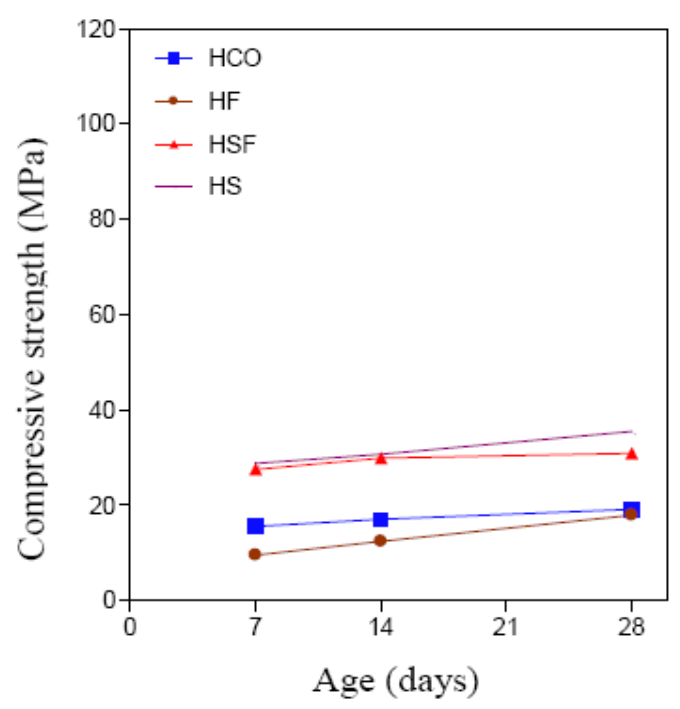

Fig. 3. Compressive strength development of OPC and alkali-activated FFA and/or GGBFS mortars at the liquid/binder ratio of 0.65 .

The analysis of these graphs shows that the compressive strength of AAFS mortars with fly ash/slag ratios of 50/50 
and $0 / 100$ is higher than that of OPC mortars and AAFS mortars with fly ash/slag ratios of $100 / 0$ has the lowest compressive strength in all mixes. The compressive strength increases with a decreasing liquid/binder ratio, however, at the liquid/binder ratios of 0.5 and 0.35 , not much difference exists in compressive strength among AAFS mortars with the same mixing ratio. At the liquid/binder ratios of $0.35,0.5$ and 0.65 , the compressive strengths of AAFS mortars with fly ash/slag ratios of 50/50 are approximately $2.1,3.5$, and 1.6 times as those of OPC mortars at ages of 28 days, respectively. The high compressive strength of alkali-activated fly ash/slag based-materials is attributed to the amorphous hydrated alkali-aluminosilicate produced for fly ash [24] and the calcium silicate hydrate gel (C-S-H) formed for slag [25]. The compressive strength of alkali-activated fly ash mortars is lower than that of OPC or alkali-activated fly ash/slag mortars because of the lower activity of fly ash. The key factors affecting the potential reactivity of fly ash include the vitreous phase content, reactive silica content, and the particle size distribution [26]. Generally, glassy surface layer of glass beads is dense and stable, which protects the inside constituents. Meanwhile, its silica-alumina glassy chain of high $\mathrm{Si}, \mathrm{Al}$, and low $\mathrm{Ca}$ is firm; the chain must be disintegrated if activity is to take place [27]. In addition, the particle size of fly ash is bigger than that of slag, leading to a reduction in the compressive strength.

\section{B. Water Absorption}

Table III lists the water absorption of OPC and AAFS mortars. It can be seen that the water absorption of AAFS mortars is lower than that of OPC mortars. At the same liquid/binder ratio, higher water absorption has been observed in alkali-activated fly ash mortars than comparable alkali-activated fly ash/slag mortars. Meanwhile, AAFS mortars with alkali-activated GGBFS have the lowest water absorption in all mixes. The water absorption of AAFS mortars at liquid/binder ratio of 0.35 (LS, LFS, and LF) varied from $2.5 \%$ to $3.8 \%$, whereas the LCO mortars had the water absorption of $6.1 \%$.

TABLE III: WATER ABSORPTION OF OPC AND AAFS MORTARS

\begin{tabular}{|c|c|c|}
\hline Mix & Water absorption (\%) & $\begin{array}{c}\text { Relative reduction } \\
\text { percentage (\%) }\end{array}$ \\
\hline LCO & 6.1 & 100.0 \\
\hline LF & 3.8 & 37.7 \\
\hline LSF & 3.2 & 47.5 \\
\hline LS & 2.5 & 59.0 \\
\hline MCO & 7.5 & 100 \\
\hline MF & 6.1 & 18.7 \\
\hline MSF & 1.4 & 81.3 \\
\hline MS & 1.3 & 82.6 \\
\hline HCO & 9.0 & 100 \\
\hline HF & 8.0 & 11.1 \\
\hline HSF & 4.7 & 47.8 \\
\hline HS & 2.6 & 71.1 \\
\hline
\end{tabular}

The water absorption of AAFS mortars at liquid/binder ratio of 0.5 (MS, MFS, and MF) varied from $1.3 \%$ to $6.1 \%$, whereas the MCO mortars had the water absorption of $7.5 \%$. When the liquid/binder ratio increases from 0.5 to 0.65 , the water absorption of AAFS mortars (HS, HFS, and HF) varied from $2.6 \%$ to $9.0 \%$. The higher water absorption in alkali-activated fly ash mortars can be predicted by considering the binder chemistry; the slag-rich systems predominantly form a C-(A)-S-H gel with a significant bound water content, while the fly ash-rich systems form N-A-S-(H), with a lower bound water content [28]. Furthermore, slag has a much finer particle size which can fill the pore and result in lower water absorption in AASF mortars.

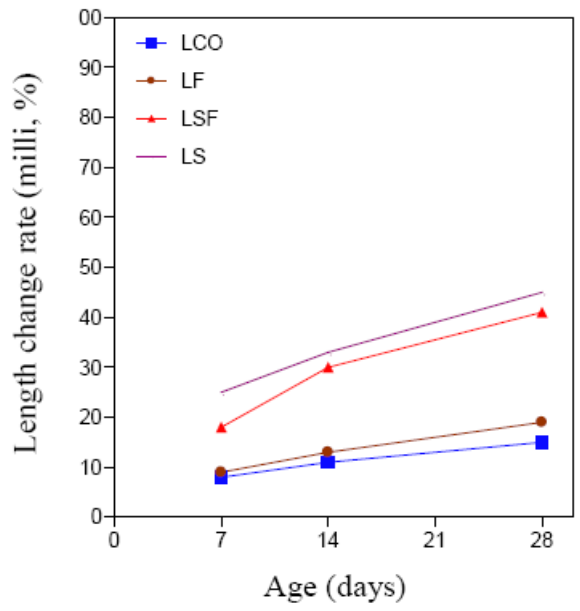

Fig. 4. Length change rate of OPC and alkali-activated FFA and/or GGBFS mortars vs. ages at the liquid/binder ratio of 0.35 .

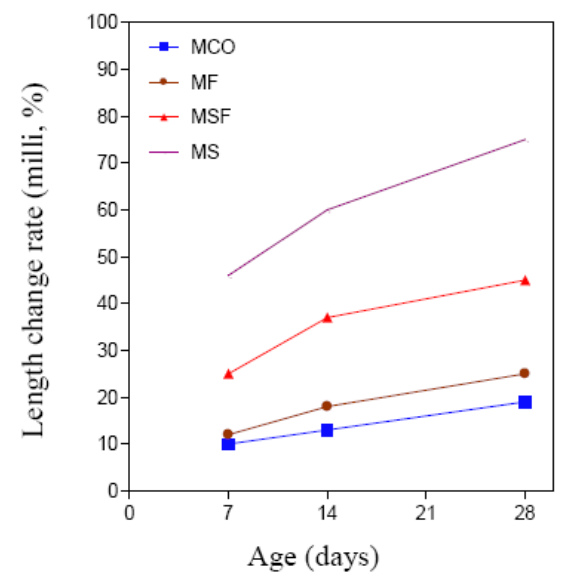

Fig. 5. Length change rate of OPC and alkali-activated FFA and/or GGBFS mortars vs. ages at the liquid/binder ratio of 0.5 .

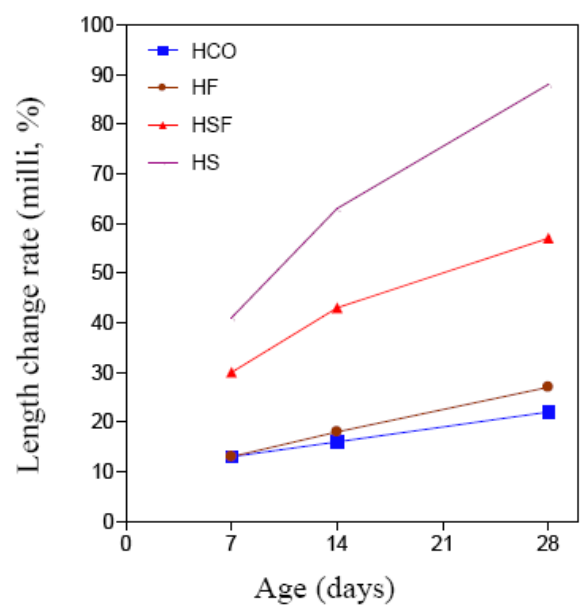

Fig. 6. Length change rate of OPC and alkali-activated FFA and/or GGBFS mortars vs. ages at the liquid/binder ratio of 0.65 .

\section{Drying Shrinkage}

Drying shrinkage is an important technical parameter influencing structural properties and durability of the 
material. The drying shrinkage or length change rate of OPC mortars and AASF mortars at 7, 14 and 28 curing days is shown in Fig. 4 - Fig. 6. The length change rate of all specimens increases with the increasing age and liquid/binder ratio. Meanwhile, AASF mortars have higher length change rate than OPC mortars ( $\mathrm{LCO}, \mathrm{MCO}$, and $\mathrm{HCO}$ ) at all ages. At the same liquid/binder ratio, higher length change rate has been observed in alkali-activated slag mortars than comparable alkali-activated fly ash/slag mortars. The greater the amount of fly ash the lower the length change rate of AAFS mortars. It indicates the fly ash/slag ratio has a significant influence on the drying shrinkage of AAFS mortars and the addition of fly ash can reduce length change rate. From these graphs, it is worth notice that AAFS mortars with fly ash/slag ratios of 100/0 (LF, MF, and HF) show almost identical length change rate as OPC mortars (LCO, $\mathrm{MCO}$, and $\mathrm{HCO}$ ). Chemical shrinkage is a reduction in volume resulting from the chemical reaction between the reagent and water. The main products of alkali-activated are hydrotalcite and C-S-H gel, which lead to an increase in the total amount of chemical shrinkage. The results obtained in this study are in agreement with the previous research [25].

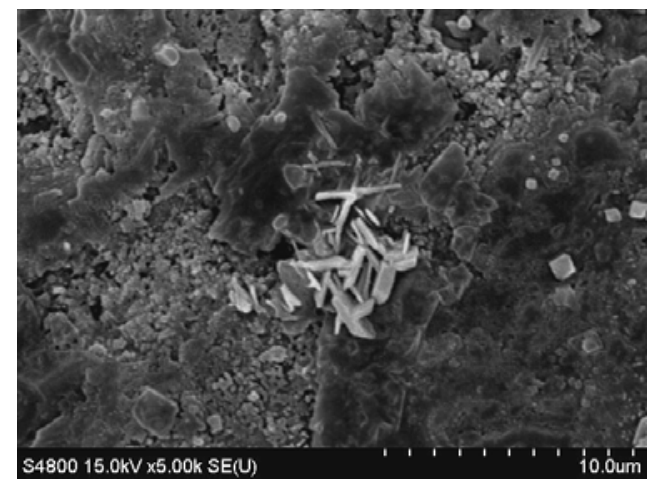

Fig. 7. SEM image of AASF mortars with fly ash/slag ratios of 50/50 (MFS) at the liquid/binder ratio of 0.5 at the age of 7 days at $5 \mathrm{~K} x$.

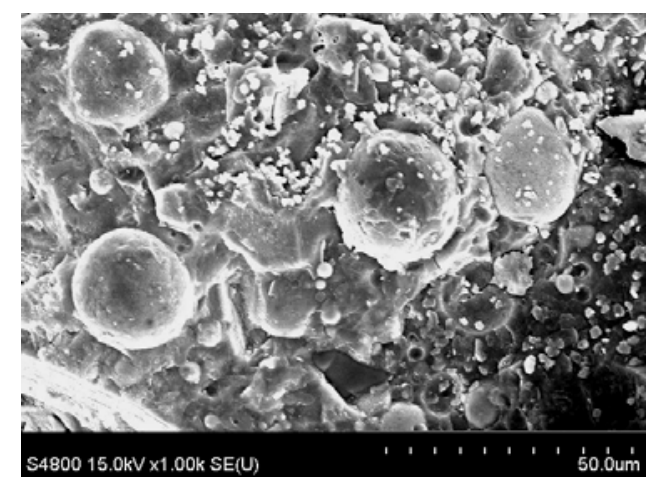

Fig. 8. SEM image of AASF mortars with fly ash/slag ratios of 50/50 (MFS) at the liquid/binder ratio of 0.5 at the age of 28 days at $1 \mathrm{~K} x$.

\section{Scanning Electron Microscopy (SEM)}

The SEM image of AASF mortar with fly ash/slag ratios of $50 / 50$ at the ages of 7 and 28 days is shown in Fig. 7 - Fig. 8 . The strip crystals are evident in Fig. 7. These crystals are mainly rich in $\mathrm{Na}$ and $\mathrm{Ca}$ and they are probably carbonates. GGBFS contains calcite whereas sodium carbonate could also be formed by free sodium available in the matrix. Particles of fly ash covered with the glassy crust have been observed in Fig. 8. It can be seen that some fly ash stays no reacted and some particles are reaction products from fly ash.
The main reaction products include two different products. One is the amorphous alkaline aluminosilicate with a 3D structure as a zeolitic gel type, which is a consequence of the alkali-activated FFA. The other is a low-crystalline calcium silicate hydrate with a dreierketten type structure, which is formed by the alkaline activation of GGBFS [29].

\section{E. X-Ray Diffraction (XRD) Analysis}

The XRD patterns of AASF mortars with fly ash/slag ratios of $50 / 50$ at the ages of 7, 14, and 28 days are shown in Fig. 9. Symbol description on the XRD patterns of products is listed in Table IV. It can be seen that the main hydration products included $\mathrm{SiO}_{2}, \quad \mathrm{C}-\mathrm{S}-\mathrm{H}, \quad \mathrm{CaAl}_{2} \mathrm{Si}_{2} \mathrm{O}_{8} \cdot 4 \mathrm{H}_{2} \mathrm{O}$, $\mathrm{NaAl}\left(\mathrm{SO}_{4}\right)_{2} \cdot 6 \mathrm{H}_{2} \mathrm{O}, \mathrm{Al}\left(\mathrm{SO}_{4}\right)(\mathrm{OH}) \cdot 5 \mathrm{H}_{2} \mathrm{O}, \mathrm{NaAl}\left(\mathrm{SO}_{4}\right)_{2} \cdot 6 \mathrm{H}_{2} \mathrm{O}$, $\mathrm{H}_{2} \mathrm{~S}$, and $\mathrm{NaAl}\left(\mathrm{SO}_{4}\right)_{2} \cdot 6 \mathrm{H}_{2} \mathrm{O}$. At the age of 7 days, the characteristic peaks of silicon dioxide $\left(\mathrm{SiO}_{2}\right)$ and zeolite gismondite $\left(\mathrm{CaAl}_{2} \mathrm{Si}_{2} \mathrm{O}_{8} \cdot 4 \mathrm{H}_{2} \mathrm{O}\right)$ exist. At 14 and 28 days of hydration, the characteristic peak of $\mathrm{SiO}_{2}$ and $\mathrm{CaAl}_{2} \mathrm{Si}_{2} \mathrm{O}_{8} \cdot 4 \mathrm{H}_{2} \mathrm{O}$ still exist. The hydration products of alkali-activated fly ash and slag are different. It is well known that $\mathrm{C}-\mathrm{S}-\mathrm{H}$ is the major binding phase in alkali-activated slag, whereas the amorphous aluminosilicate polymeric matrix (geopolymer) is primary alkali-activated fly ash [30].

\begin{tabular}{|c|c|}
\hline Symbol & Chemical compounds of formula \\
\hline $\mathrm{A}$ & $\mathrm{CaO} \cdot \mathrm{Al}_{2} \mathrm{O}_{3} \cdot 4 \mathrm{SiO}_{2} \cdot 2 \mathrm{H}_{2} \mathrm{O}$ \\
\hline $\mathrm{B}$ & $\mathrm{CaAl}_{2} \mathrm{Si}_{3} \mathrm{O}_{10} \cdot 6 \mathrm{H}_{2} \mathrm{O}$ \\
\hline $\mathrm{C}$ & $\mathrm{CaAl}_{2} \mathrm{Si}_{2} \mathrm{O}_{8} \cdot 4 \mathrm{H}_{2} \mathrm{O}$ \\
\hline $\mathrm{D}$ & $\mathrm{SiO}_{2}$ \\
\hline $\mathrm{E}$ & $\mathrm{KAl}\left(\mathrm{SO}_{4}\right)_{2} \cdot 12 \mathrm{H}_{2} \mathrm{O}$ \\
\hline $\mathrm{F}$ & $\mathrm{Al}\left(\mathrm{SO}_{4}\right)(\mathrm{OH}) \cdot 5 \mathrm{H}_{2} \mathrm{O}$ \\
\hline G & $\mathrm{NaAl}\left(\mathrm{SO}_{4}\right)_{2} \cdot 6 \mathrm{H}_{2} \mathrm{O}$ \\
\hline $\mathrm{H}$ & $\mathrm{H}_{2} \mathrm{~S}$ \\
\hline I & $\mathrm{Na}_{3} \mathrm{MgAlSi}_{2} \mathrm{O}_{8}$ \\
\hline $\bar{J}$ & $\mathrm{MgSO}_{4} \cdot 7 \mathrm{H}_{2} \mathrm{O} \cdot \mathrm{MgSO}_{4} \cdot \mathrm{H}_{2} \mathrm{O} \cdot \mathrm{MgSO}_{3} \cdot 3 \mathrm{H}_{2} \mathrm{O}$ \\
\hline
\end{tabular}

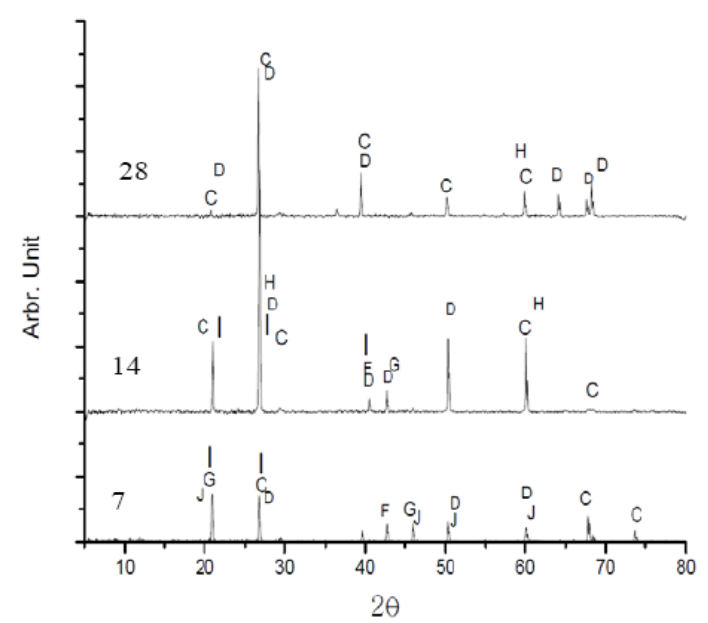

Fig. 9. XRD patterns of AASF mortars with fly ash/slag ratios of 50/50 at the liquid/binder ratio of 0.5 at the ages of 7,14 , and 28 days.

\section{CONCLUSIONS}

This study presents an investigation into mechanical and microstructural characterization of alkali-activated materials 
based on fly ash and slag. Both fly ash/slag ratio and the liquid/binder ratio are significant factors influencing the properties of AAFS mortars. Except alkali-activated fly ash mortars, higher compressive strengths have been observed in alkali-activated GGBFS and AAFS mortars than comparable OPC mortars. The water absorption of AAFS mortars is lower than that of OPC mortars. However, AAFS mortars has higher length change rate than OPC mortars. The greater the amount of fly ash the lower the length change of AAFS mortars. The hydration products of AAFS mortars are mainly amorphous alkaline aluminosilicate and low-crystalline calcium silicate hydrate gel. AAFS mortars with a fly ash/slag ratio of 50/50 and at an liquid/binder ratio of 0.5 may be considered as the optimum mix design based on this study.

\section{ACKNOWLEDGEMENT}

The financial support from the National Science Council under grant number NSC 102-2221-E-274-007 is gratefully acknowledged.

\section{REFERENCES}

[1] M. C. G. Juenger, F. Winnefeld, J. L. Provis, and J. Ideker, "Advances in alternative cementitious binders," Cement and Concrete Research, vol. 41, pp. 1232-1243, 2011

[2] A. F. Jime'nez and A. Palomo, "Characterisation of fly ashes. Potential reactivity as alkaline cements," Fuel, vol. 82, pp. 2259-2265, 2003.

[3] J. I. E. Garcia, L. J. E. Perez, A. Gorokhovsky, and L. Y. G. Zamorano, "Coarse blast furnace slag as a cementitious material, comparative study as a partial replacement of Portland cement and as an alkali activated cement," Construction and Building Materials, vol. 23, pp. 2511-2517, 2009.

[4] S. A. Bernal, J. L. Provis, V. Rose, and R. M. d. Gutierrez, "Evolution of binder structure in sodium silicate-activated slag-metakaolin blends," Cement and Concrete Composites, vol. 33, pp. 46-54, 2011.

[5] J. Wang, X. L. Wu, J. X. Wang, C. Z. Liu, Y. M. Lai, Z. K. Hong, and J. P. Zheng, "Hydrothermal synthesis and characterization of alkali-activated slag-fly ash-metakaolin cementitious materials," Microporous and Mesoporous Materials, vol. 155, pp. 186-191, 2012.

[6] M. B. Haha, G. L. Saout, F. Winnefeld, and B. Lothenbach, "Influence of activator type on hydration kinetics, hydrate assemblage and microstructural development of alkali activated blast-furnace slags," Cement and Concrete Research, vol. 41, pp. 301-310, 2011.

[7] D. Krizana, and B. Zivanovic, "Effects of dosage and modulus of water glass on early hydration of alkali-slag cements," Cement and Concrete Research, vol. 32, pp. 1181-1188, 2002.

[8] X. Yang, W. Ni, X. Zhang, and Y. Wang, "Effect of alkali-activation on aluminosilicate-based cementitious materials," Journal of Beijing University of Science and Technology, vol. 15, no. 6, pp.796-801, 2008.

[9] M. Chi and R. Huang, "Binding mechanism and properties of alkali-activated fly ash/slag mortars," Construction and Building Materials, vol. 40, pp. 291-298, 2013.

[10] M. Chi, "Effects of dosage of alkali-activated solution and curing conditions on the properties and durability of alkali-activated slag concrete," Construction and Building Materials, vol. 35, pp. 240-245, 2012.

[11] F. Collins and J. G. Sanjayan, "Strength and shrinkage properties of alkali-activated slag concrete containing porous coarse aggregate," Cement and Concrete Research, vol. 29, pp. 607-610, 1999.

[12] A. F. Jimenez, J. G. Palomo, and F. Puertas, "Alkali-activated slag mortars mechanical strength behaviour," Cement \& Concrete Research, vol. 29, no. 8, pp. $1313-1321,1999$.

[13] H. Mingyu, Z. Xiaomin, and L. Fumei, "Alkali-activated fly ash-based geopolymers with zeolite or bentonite as additives," Cement and Concrete Composites, vol. 31, pp. 762-768, 2009.

[14] A. Palomo et al., "Alkali-activated fly ashes: A cement for the future," Cement and Concrete Research, vol. 29, pp. 1323-1329, 1999.
[15] Z. Xie and Y. X., "Hardening mechanisms of an alkaline activated class F fly ash," Cement and Concrete Research, vol. 31, pp. 1245-1249, 2001.

[16] F. Puertas et al., "Alkaliactivated fly ash/slag cements. Strength behaviour and hydration products," Cement and Concrete Research, vol. 12, no. 8, pp. 1625-1632, 2000.

[17] F. Q. Zhao et al., "Activated fly ash/slag blended cement," Resources, Conservation and Recycling, vol. 52, pp. 303-313, 2007.

[18] C. Shi and R. Day, "Early strength development and hydration of alkali-activated blast furnace slag/fly ash blends," Advances in Cement Research, vol. 11, no. 4, pp. 189-196, 1999.

[19] Standard Test Method for Compressive Strength of Hydraulic Cement Mortars, ASTM C109-2011.

[20] Standard Test Method for Density, Absorption, and Voids in Hardened Concrete, ASTM C642-2006.

[21] H. Li and H. Sun, "Microstructure and cementitious properties of calcined clay-containing gangue," International Journal of Minerals, Metallurgy and Materials, vol. 16, no. 4, pp. 482-486, 2009.

[22] Standard Test Method for Drying Shrinkage of Mortar Containing Hydraulic Cement, ASTM C 596-2009.

[23] S. D. Wang, K. L. Scrivener, and P. L. Pratt, "Factors affecting the strength of alkali activated slag," Cement \& Concrete Research, vol. 24, pp. $1033-1043,1994$.

[24] D. Khale and R. Chaudhary, "Mechanism of geopolymerization and factors influencing its development: a review," Journal of Material Science, vol. 42, pp. 729-746, 2007.

[25] V. D. Glukhovshy, Soil Silicates, Kiev(Ukraine): Gosstroy, 1959.

[26] A. Ferna'ndez-Jime'nez, A. Palomo, and M. Criado, "Microstructure development of alkali-activated fly ash cement: a descriptive model," Cement and Concrete Research, vol. 35, pp. 1204-1209, 2005.

[27] Y. Fan et al., "Activation of fly ash and its effects on cement properties," Cement and Concrete Research, vol. 29, pp. 467-472.

[28] J. L. Provis et al., "X-ray microtomography shows pore structure and tortuosity in alkali-activated binders," Cement and Concrete Research, vol. 42, pp. 855-864, 2012.

[29] M. Chi and R. Huang, "Effects of dosage and modulus ratio of alkali-activated solution on the properties of slag mortars," Advanced Science Letters, vol. 16, no. 1, pp. 7-12, 2012.

[30] F. Puertas and A. Fernandez-Jimenez, "Mineralogical and microstructural characterisation of alkali-activated fly ash/slag pastes," Cement \& Concrete Composites, vol. 25, pp. 287-292, 2003.

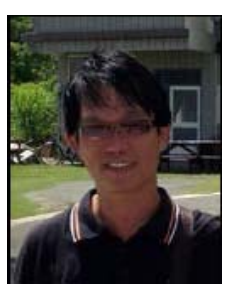

Maochieh Chi received his Ph.D. and M.D. degrees in civil engineering from the Department of Harbour and River Engineering, National Taiwan Ocean University, Keelung, Taiwan. $\mathrm{He}$ is an associate professor of the Department of Fire Science at WuFeng University, Taiwan. $\mathrm{He}$ is an active researcher and instructor on topics including physical and mechanical properties, microstructure and durability of concrete, high performance concrete, environmentalism-conscious design, and green concrete.

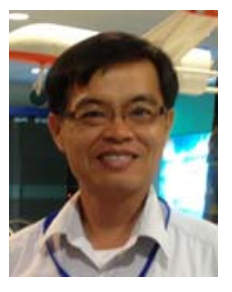

Yenchun Liu received his Ph.D. degree in chemical engineering from the Department of Chemical Engineering, National Tsing Hua University, Hsinchu, Taiwan. He is an associate professor of the Graduate School of Opto-Mechatronics and Materials at WuFeng University, Taiwan. His research interests include energy and sustainable development, green technology, lithium ion batteries materials, nanoscience \& nanotechnology and chemical engineer.

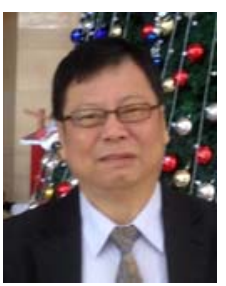

Ran Huang received his Ph.D. degree in civil engineering from the Department of Civil Engineering, University of Texas, U.S.A. He is a professor of the Department of Harbour and River Engineering, National Taiwan Ocean University, Taiwan. He is an active researcher and his research interests include mechanics of materials and structures, composite materials, micromechanics, durability of concrete, high performance concrete, green concrete, and sustainable 